\title{
BIBLIOTECA GRAMSCIANA: OS LIVROS DA PRISÃO DE ANTONIO GRAMSCI
}

\author{
Lincoln Secco \\ Depto. de História - FFLCH/USP
}

\section{Resumo}

Este artigo apresenta as conclusões preliminares de uma pesquisa sobre os livros da biblioteca da prisão lidos por Antonio Gramsci. Tendo a sua disposição apenas alguns livros de autores marxistas, Gramsci foi capaz de refletir as questões mais importantes de seu tempo. Além disso, procuro demonstrar que ele analisou os livros e seus editores como meios de ligação entre a cultura e o público.

\section{Pallavras-Chave}

História do Marxismo • História do livro • História da Itália • Fascismo • Comunismo

\section{Abstract}

This article presents preliminary conclusions from research on the books read by Antonio Gramsci in the prison library. Although he had only a few books by Marxist authors at his disposal, Gramsci still was able to face the most important issues of his time. In addition, the article argues that in his Prison Notebooks, Gramsci analyzed these books and their publishers as a means of showing the link between culture and the public.

\section{Keywords}

History of Marxism • History of Book • History of Italia • Fascism • Communism 
A História do livro e da leitura constituiu um campo de estudo de muitas possibilidades analíticas. Numa zona intermediária que une a História Social e a História Econômica, ela tem inspirado estudos sobre livrarias, livreiros, editoras, bibliotecas ${ }^{1}$. É também um ramo fecundo para iluminar novas facetas da Revolução Francesa (por exemplo, os estudos de Robert Darnton), da História Cultural (Roger Chartier), da História Antiga (Luciano Cânfora e Guglielmo Cavallo). Desde o clássico de Daniel Mornet (As origens intelectuais da Revolução Francesa), foi possível ampliar muito o conhecimento das relações (nem sempre tão diretas) entre as luzes e a Revolução.

No que tange à cultura operária e ao socialismo, N. Richter na França é um exemplo dessa modalidade de abordagem. Na obra coletiva "História do Marxismo", organizada por Eric Hobsbawm, encontram-se artigos acerca dessa mesma temática. No Brasil, salvo estudos pioneiros de Astrojildo Pereira e Edgard Carone, pouco ainda se fez sobre a História dos livros e editoras de esquerda ou operárias ${ }^{2}$.

Também nesta área, Antonio Gramsci foi um pioneiro. Ele tem sido visto como objeto de uma história mais ampla que a História do Livro, ou seja, a da

210 Recepção e difusão de suas idéias em várias partes do mundo. A Bibliografia feita por John Cammett arrola milhares de títulos sobre Gramsci, muitos deles tratando da fortuna crítica de seus livros. Todavia, Gramsci ele mesmo refletiu sobre os livros e a história deles. Ele percebeu a obra impressa como um meio fundamental na constituição da cultura política. Até porque o socialismo marxista nascia como um pensamento vinculado a uma prática política.

Filosofia da práxis é a expressão que Gramsci usava para se referir ao marxismo em seus Cadernos do Cárcere. A práxis ocupa lugar central não só na reflexão de Gramsci como no próprio pensamento marxista em geral. O termo é essencial para se entender o papel que desempenhou na formação dos militantes sociais democratas e comunistas a literatura política inspirada em Karl

\footnotetext{
${ }^{1}$ Evidentemente, este artigo não busca fazer referências aos avanços teóricos na área específica da História do Livro senão indiretamente. Trata-se de abordar a maneira como Gramsci tratou de temas semelhantes: mediação editorial, formas de pensamento, estratégias de leitura etc.

${ }^{2}$ A esse respeito veja-se: Deaecto, Marisa e Secco, Lincoln. “A Difusão dos Livros Marxistas no Brasil”. In: Coggiola, O. (Org). América Latina. São Paulo: Xamã, 2003.
} 
Marx e em seus seguidores. Como formulação teórica, Marx o retirou de August Von Cieskowski (1838) ${ }^{3}$. Tornou-se conhecido mais entre socialistas graças às teses sobre Feuerbach, escritas por Marx e publicadas por Engels no final do século. Antônio Labriola usou o termo na Itália.

Como unidade entre teoria e prática, pensamento e ação, o marxismo apareceu como filosofia que aspirou intervir permanentemente na realidade. Para ser prática pensada e pensamento praticado, o marxismo precisou, todavia, se plasmar com o "sincretismo de base" de seus adeptos: o "senso comum", como diria Antonio Gramsci. Ou seja, os comunistas e socialistas em geral não eram ou não foram apenas "marxistas", e suas idéias conviviam com princípios nacionais, religiosos, científicos (ou que se pretendiam científicos) etc. Também o "marxismo" ao qual a maioria dos militantes tinha acesso não possuía o mesmo rigor dos melhores pensadores sociais. Isso é particularmente importante na medida em que o comunismo de Marx e Engels se propôs a ser a consciência teórica de uma prática social revolucionária, o que implicava diminuir (e tendencialmente eliminar) a distância entre teoria e prática, entre dirigentes e dirigidos.

Foi a existência de um número crescente de gráficas e editoras e a possibilidade igualmente crescente de que os socialistas, comunistas e anarquistas tivessem acesso tanto à edição quanto ao consumo de livros e jornais, que fizeram do marxismo uma "força material" potencial, para usar uma expressão do próprio Marx. Os livros, as editoras, tipografias e os jornais tornam-se, a um só tempo, infra-estrutura e superestrutura: as idéias só existem para o livro e este para aquelas, interagindo e se determinando reciprocamente. Daí a importância de se conhecer os formatos das brochuras, panfletos e livros. As tiragens, as traduções, o número e especialmente o local das edições. É essa materialidade sensível do livro (e, em certa medida do jornal) que confere à teoria a possibilidade de se fazer práxis.

O livro é a base mais imediata, embora nunca a única, das formas de consciência social antes do advento dos modernos meios de informação. Ele se insere num circuito global de reprodução das idéias e também de relações sociais. O conjunto destas, como diz Marx, "forma a estrutura econômica da sociedade, a base real, sobre a qual se eleva um edifício jurídico e político, e a

\footnotetext{
${ }^{3}$ Vide: Maximilien Rubel. Karl Marx: essai de biographie intellectuelle. Paris: Marcel Rivière, 1957.
} 
qual correspondem formas determinadas da consciência social" ${ }^{\text {. A circula- }}$ ção do livro (o comércio livreiro), faz parte dessa estrutura econômica ${ }^{5}$ de maneira bastante especial, porque o livro, mais que outras mercadorias (no século XIX), é um produto cujo valor de uso é portador imediato de elementos que constituem a superestrutura ideológica. Isso o particulariza, embora sua participação no conjunto da produção econômica seja pequena.

\section{Condições Políticas e Editoriais na Itália}

Os livros que Gramsci tinha no cárcere compunham um movimento editorial bastante específico na Europa Latina, especialmente na França. Os livros italianos eram de editoras que se tornariam tradicionais, como Mondadori, Bonpiani. Assim como alguns livros franceses eram de editoras como Bernard Grasset e Gaston Gallimard (o editor francês de Luigi Pirandello). Mas os livros socialistas eram preferencialmente daquelas editoras que por mais ou menos tempo dedicaram-se à literatura revolucionária, como a Marcel Rivière, Rieder e o caso extremo da Alfred Costes, que apoiou uma das mais impor212 tantes tentativas de edição das obras completas de Marx e Engels. Esta editora extinguiu-se nos anos 1950 .

A hegemonia cultural francesa era incontrastável até a Segunda Guerra Mundial. Ao menos nos países a oeste do Elba, na Europa, e também nas penínsulas Itálica e Ibérica, bem como na América Latina. Por isso, destacar o movimento editorial francês corresponde a dar relevo à maior parte das edições socialistas. Especialmente porque, na época de Gramsci, assiste-se ao declínio do papel editorial do Partido Social Democrata Alemão (SPD) e à ascensão das editoras ligadas aos partidos comunistas e, por via deles, à União Soviética e à Internacional Comunista. A Correspondance internationale e várias outras publicações oficiais da Internacional Comunista eram em francês.

O próprio Gramsci dominava perfeitamente essa língua desde o tempo em que fora jornalista e crítico literário nos jornais Avanti e Il Grido del Popolo,

\footnotetext{
${ }^{4}$ K. Marx. Oeuvres. Économie. Édition établie par Maximilien Rubel. Paris: Gallimard, 1965 (Bibliothèque de la Pléiade), pp. 272-273.

${ }^{5}$ Todavia, o próprio Gramsci considera o livro como meio material inserido no campo das superestruturas. Trata-se de uma "base material superestrutural". Veja-se a esse respeito algumas notas nos Cadernos do Cárcere.
} 
nos anos 1910. E quando se tornou dirigente do semanário L'Ordine Nuovo fez traduções de textos franceses (como os do grupo Clartè, de Henri Barbusse). O russo (que Gramsci travou contato por ter vivido na Rússia nos anos 1920) e que se transformaria, com o tempo, numa língua relativamente importante no movimento comunista internacional, só adquiriu a hegemonia de fato nos países da Europa Central e do Leste. E, mesmo assim, quando essa região tornouse socialista, depois da Segunda Guerra. Quando Gramsci escreveu seus cadernos de tradução no cárcere, ele se preocupou em aprender o alemão e o inglês. Mas isso era mais devido às suas condições e ao seu talento de intelectual nato do que ao papel político preponderante dessas línguas. Certamente, o alemão continuava sendo a referência teórica, mas já não era política.

A difusão do marxismo, portanto, teve dois veículos principais: a língua e as editoras francesas. E teve um centro irradiador: Moscou. As razões para o declínio de Berlim e do SPD alemão eram fáceis de se observar: o impacto mundial da Revolução de Outubro criara um movimento igualmente mundial nela inspirado. Nada semelhante ocorrera antes. Embora os alemães tivessem o domínio da II Internacional, a estrutura desta era bem menos centralizada. Enquanto a Internacional Comunista era um órgão dirigente de fato (e de direito, para os comunistas) dos demais partidos comunistas, que eram suas seções nacionais.

Além disso, foi difícil qualquer colaboração política entre comunistas e socialistas nos primeiros anos. Ao menos até a mudança de linha política da Internacional Comunista nos anos 1930, quando a tática de frente única antifascista foi adotada. Os autores vinculados à II Internacional ficaram definitivamente em segundo plano. Turati, na Itália, McDonald, na Inglaterra, Kautski e Bernstein, na Alemanha, eram substituídos por Lênin, Rosa Luxemburg, Trostski e, mais tarde, Stalin. Os autores sociais democratas eram apenas citados de segunda mão, normalmente a partir das críticas a eles endereçadas pelos marxistas revolucionários, como Lênin, Trotski, Bukharin, Zinoviev, Rosa Luxemburg e Franz Mehring, ou eram apenas criticados por autores revolucionários menores ou situados nas margens da atividade política revolucionária, como Paul Matick, Karl Korsh ou Anton Pannekoek.

Pela "biblioteca gramsciana" do cárcere pode-se constatar esse fato: dois títulos de Bernstein e um só de Kautski e de Turati. E se é verdade que só um título de Bukharin e nenhum de Lênin ou Zinoviev aparecem na lista organizada por Valentino Gerratana no aparato crítico da edição dos Quaderni del Carcere do Instituto Gramsci, os motivos são bem conhecidos! Afinal, Zinoviev e Bukharin, aquele mais do que este, tiveram uma circulação impressionante 
nas editoras e livrarias francesas. Ao menos até o início dos anos trinta. Também pelos poucos títulos de Stalin até o início dos anos 1930, pode-se observar que o culto da personalidade ainda não estava inteiramente instalado na União Soviética quando Gramsci foi preso, embora os boletins da oposição de esquerda formada por Trotski, Zinoviev e Kamenev já usassem, em 1927, a expressão "stalinismo".

De toda maneira, a hegemonia editorial francesa era patente na própria literatura que Gramsci usava no cárcere. O maior número de títulos que ele citou nos Cadernos era, depois do italiano, obviamente, em francês. Isso porque, segundo Edgard Carone, em 1926 começa uma nova fase editorial na França. O Bureau d'Editions herda o catálogo da Librarie de l'Humanité e publica vários teóricos do marxismo. Ele se volta para as questões de organização. As Editions Sociales Internationales editam Marx e Lênin, principalmente. Mas também os romances proletários. Nas franjas dessa atividade editorial dominante na esquerda, aparecem a Librarie du Travail, que continua a publicar trabalhos sobre sindicatos, a Rieder, que traduz e edita os livros de Trostski e a Félix Alcan, que dá vazão às teses universitárias sobre marxismo ${ }^{6}$.

214 E o que se tem na Itália? As editoras, a exemplo da França, mantêm uma organização considerável, mas com um público leitor muito menor. Desde os anos 1870, a Associazione Tipografico-Libraria organiza muitos congressos e edita o Giornale della Libreria. Além disso editou o Catalogo Generale della Libreria Italiana dal 1847 al 1899. Um dicionário italiano do princípio do século XX nomeava entre as mais importantes editoras italianas: Nicolò Zanichelli (Bologna), Antonio Vallardi (Milano), Loesscher (Torino), G. Laterza (Bari), Sansoni (Firenze) ${ }^{7}$. A Mondadori, também de Milano, fora fundada em 1907. Em 1929, um de seus funcionários (Valentino Bonpiani) fundou outra editora, a Bonpiani, também em Milano ${ }^{8}$. Outras, como a editora dos Irmãos Bocca (Torino), interessaram a Gramsci tanto pelo conteúdo quanto pela ação editorial. Além de alguns livros de Robert Michels e de Loria (autor ao qual se fará referência mais adiante), eles publicaram as obras de Max Nordau (depois passaram “às

\footnotetext{
${ }^{6}$ Edgard Carone. O marxismo no Brasil. Rio de Janeiro: Dois Pontos, pp.40-42.

${ }^{7}$ A. Brunacci. Dizionario generale di cultura. Torino: Libreria Editrice, 1915, pp.498-9.

${ }^{8}$ Caro Bonpiani. Lettere com l'editore. Milano: Bonpiani, 1988, p.3.
} 
mãos de editores do tipo Madela e Barion e foram lançadas aos vendedores ambulantes a preços baixíssimos em grande quantidade)"’.

Tudo isso revela a amplitude geográfica do movimento editorial. Mas ainda assim, não se podiam esconder por trás dessa variedade as debilidades educacionais da população. $75 \%$ dos italianos eram analfabetos à época da unificação e só 2,4\% dominavam o idioma oficial (toscano). Essa situação melhorou sensivelmente na era de Giolitti, mas até a Segunda Guerra era frágil a situação social e educacional do país. No campo da produção editorial, essa fragilidade educacional se refletia. A produção editorial era de 6.822 títulos em 1906 e permaneceu quase a mesma (6.832) em 1909. Os editores argumentavam, entretanto, que somente $10 \%$ desses títulos se mantinham com venda constante por um ou dois anos ${ }^{10}$.

O período em que Gramsci permaneceu preso assistiu a um aumento da média anual de publicações de livros. No intervalo 1922-26 a média anual foi de 6.700 livros publicados. No período 1927-31, a média subiu a 9.568. Depois, entre 1932-36, a média foi de 12.656. Até a Guerra o volume de edições incrementou-se mais ainda.

Os dados acima excluem os livros escolares. Se olharmos apenas para o ano singular de 1933, quando o número de livros editados chegou a 13.975, poderemos observar aquilo que foi uma tendência persistente daquele e dos outros anos. A maioria dos livros era de ciências morais, sociais e políticas $(32,93 \%)$, depois literatura $(22,91)$, artes $(15,70 \%)$ e didáticos $(11,96 \%)$. Apesar das oscilações, apenas os livros escolares sofreram uma queda acentuada até o fim da Segunda Guerra.

De fato, a Itália teve um aumento da produção editorial sem par no período 1928-32, os anos mais produtivos da atividade carcerária de Gramsci. Enquanto a produção francesa estava estagnada em 72.044 (praticamente o mesmo número que nos anos anteriores 1922-27), a da Alemanha caía para 127.283 (contra 142.166 nos anos anteriores), a Itália saltava de 33.967 a 54.265, atrás apenas da Grã-Bretanha (que subira de 65.791 a 73.400$)^{11}$.

\footnotetext{
${ }^{9}$ Antonio Gramsci. Quaderni del carcere. A cura di Valentino Gerratana. Torino: Einaudi, 1977, p. 1900. Doravante os Quaderni serão citados: Q.C.

${ }^{10}$ Concetto Pettinato. "Libri, editori ed autori", La Lettura, Revista Mensile del Corriere della Sera, N. 10, outubro de 1910.

${ }^{11}$ Marco Santoro. Storia del libro italiano. Milano: Editrice Bibliografica, 2000, pp.318-19.
} 
Gramsci chegou a por em dúvida dados como estes, lembrando que seria preciso avaliar o conteúdo e a natureza dessas publicações. A análise quantitativa precisava combinar-se à qualitativa.

\begin{abstract}
"Insiste-se muito sobre o fato do aumento do número de livros publicados. O Instituto Italiano do Livro comunica que a média anual do decênio 1908-1918 foi exatamente de 7.300. Os cálculos feitos para 1929 (ou mais recentes) dão a cifra de 17.718 (livros e opúsculos; exceto aqueles do Vaticano e de São Marino, das colônias e das terras de língua italiana que não fazem parte do reino). Publicações polêmicas e, portanto, tendenciosas". ${ }^{12}$
\end{abstract}

Gramsci afirma que seria necessário ver se as cifras são calculadas hoje como no passado e ver se mudou a "composição orgânica do complexo livreiro". Ele cita a multiplicação de casas editoras católicas que editam, muitas vezes, livros sem nenhuma importância cultural. Por fim, seria preciso também inserir nas estatísticas as tiragens, e isto especialmente para os jornais e revistas:

"Lê-se muito ou pouco? E o que se lê mais? Está se formando uma classe média culta mais numerosa que no passado, que lê mais, enquanto as classes populares lêem muito menos; isto aparece na relação entre livros, revistas e jornais. Os jornais diminuíram em número e imprimem menos cópias; lêem-se mais revistas e livros (isto é, há mais leitores de revistas e livros). Confronto entre a Itália e outros países nos modos de fazer a estatística livreira e nas classificações por grupos do que se publica" ${ }^{\prime 3}$.

\title{
Primeiras Leituras na Prisão
}

Nos cerca de dez anos em que esteve no cárcere fascista (1926-1937), Antonio Gramsci escreveu os Cadernos do Cárcere. Sob a rigorosa censura carcerária ele não podia obter muitas informações acerca dos fatos cotidia-

\footnotetext{
${ }^{12}$ Q.C., p. 1699-1700.

${ }^{13}$ Q.C., p. 1699-1700.
} 
nos, o que corrigia parcialmente com um número elevado de assinaturas de revistas que se lhe permitiam ler.

Desde suas primeiras missivas, ele se preocupou muito com o fornecimento de livros e periódicos. Na prisão de Ustica $(9 / 12 / 26)^{14}$, quando lia $O$ homem que queria ser rei, de Kipling, pediu com urgência os dicionários e gramáticas para seus estudos de alemão, o que denota seu interesse em aprofundar-se na língua em que ainda estava boa parte dos escritos de Marx e Engels. Também os livros sobre o Risorgimento e a unidade nacional, tema que ele já vinha tratando pouco antes de ser preso, quando escrevia "Alguns temas da questão meridional". Em outras cartas ele fez observações sutis acerca dos diferentes grupos regionais e culturais do sul da Itália.

A primeira fonte para Gramsci foi a Biblioteca da prisão. Essa circunstância limitou e, ao mesmo tempo, estimulou a reflexão teórica. Eis um caso em que o conteúdo, bem como a forma (leggere senza scrivere) determinou uma nova abordagem da literatura. Numa carta de 22 de abril de 1929, Gramsci informa a Tatiana que era preciso abandonar o modo de pensar escolástico e não por na cabeça a idéia de se fazer estudos regulares e aprofundados, porque isso seria impossível até para aqueles que estavam em melhores condições do que ele. Exceto no caso do estudo das línguas modernas, para o qual bastaria uma gramática, que se poderia encontrar em qualquer banca de livros usados por preço barato (na expressão do próprio Gramsci), embora não se pudesse aprender a pronúncia.

Além disso, muitos encarcerados subestimavam a biblioteca carcerária. Certo, diz Gramsci, ela é desconexa, os livros são recolhidos ao acaso e abundam livros de devoção e romances de baixa condição. Ele leu os romances populares aos montes: Sue, Montépin, Ponson etc. Em geral, lia-os em francês. Mas os romances populares em italiano eram editados pelo jornal Corriere. Publicava ao menos 15 ao ano em tiragens altíssimas. Seguia-o a Casa Sozogno.

Mas essa restrição inicial aos livros da biblioteca da prisão não impediu que Gramsci, mesmo sem poder fazer apontamentos, chegasse a perguntas que se

\footnotetext{
${ }^{14}$ Todas as cartas citadas a seguir provêm das seguintes fontes: Q.C., V. IV. Vide também: Antonio Gramsci. Lettere dal Carcere. Torino: Einaudi, 1978, 303 páginas. Antonio Gramsci. Novas cartas de Gramsci e algumas de Piero Sraffa. Rio de Janeiro: Paz e Terra, 1987, 116 páginas.
} 
tornaram verdadeiros problemas de pesquisa: "Por que esta literatura é sempre a mais lida e a mais editada? A quais necessidades satisfaz? A quais aspirações corresponde?". Ao comentar a atividade editorial da casa Sozogno ele disse:

"Um confronto no tempo de atividade editorial da Casa Sozogno daria um quadro bastante aproximativo das variações do gosto popular; a pesquisa é difícil, porque a Sozogno não imprime o ano de publicação e não numera freqüentemente as reimpressões, mas um exame crítico dos catálogos daria algum resultado" ${ }^{15}$.

Como se nota, "O cuidado e a atenção com os quais Gramsci registra rigorosamente cada detalhe bibliográfico são surpreendentes" 16 .

Outro exemplo, indicado por Gramsci, é o do historiador Groethuysen que, para estudar a burguesia nos dois séculos antes de 1789, leu toda uma literatura de devoção, prédicas, catecismos de diversas dioceses, e fez um "magnífico volume" (na expressão de Gramsci).

O principal intermediário de Gramsci nas compras de livros era Piero

218 Sraffa, professor de economia em Cambridge e amigo de Maurice Dobb. Direta ou indiretamente eles sempre mantiveram discussões dessa natureza. Como Gramsci tinha um limite definido para escrever cartas, a correspondência era na maioria das vezes mediada por sua cunhadaTatiana Schucht. Piero Sraffa abrira uma conta corrente ilimitada para Gramsci na livraria milanesa Sperling e Kupfer. Em 21/12/26 Gramsci escreveu:

"Carissimo amigo, recebi a tua carta de 13; não recebi ainda os livros que me anunciou. Eu te agradeço muito cordialmente pela oferta que me fez; já escrevi à Livraria Sperling e fiz um pedido bastante vistoso, seguro de não ser indiscreto, porque conheço toda a tua gentileza".

Em seguida (2/1/27) ele informou a Piero Sraffa ter recebido os livros:

\footnotetext{
${ }^{15}$ Q.C., p. 2125.

${ }^{16}$ Joseph Buttigieg. "O método de Gramsci”, Educação em foco, Universidade Federal de Juiz de Fora, V. 5, N. 2, fevereiro de 2001, p.20.
} 
"Assim, vou ler abundantemente por algum tempo. Eu te agradeço a gentileza, mas não queria abusar. Asseguro-te, todavia, que francamente me reportarei a ti algumas vezes em que tiver necessidade de qualquer coisa".

Numa carta de 4 de abril de 1927 ele informa que possui alguns livros dele mesmo e que toda semana recebe 8 livros da Biblioteca do Cárcere:

"Para você ter uma idéia, faço-lhe a lista dessa semana que, porém, é excepcional pela relativa bondade dos livros conseguidos: 1 . Pietro Colletta, Storia del Reame di Napoli (ótimo); 2. V. Alfieri, Autobiografia; 3. Molière, Commedie scelte, traduzidas pelo Senhor Moretti (tradução ridícula); 4. Carducci, dois volumes das Obras completas (medíocres, entre os piores de Carducci); 5. Artur Lévy, Napoleone intimo (curioso, apologia de Napoleão como "homem moral"); 6. Gina Lombroso, Nell' America meridionale (medíocre); 7. Harnack, L'Essenza del cristianesimo; Virgilio Brocchi, Il destino in pugno, romance (torna possessos até os cães); Salvador Gotta, La donna mia (... tedioso)”.

Gramsci informa uma lista insuspeita para seus censores. Revela-se ainda apenas um leitor. E sua leitura tem tanto o interesse de futuras pesquisas quanto de prazer estético ou intelectual. É que pouco tempo antes (março de 1927) ele havia feito uma requisição para escrever na sua cela. Foi indeferida. Em 20 de fevereiro de 1928, ele escreveu à sua cunhada: "Posso ler, mas não posso estudar, porque não me foi concedido o direito de ter papel e tinta a minha disposição". Uma nova requisição encaminhada pela sua família no ano seguinte obteve a permissão. Em 24 de setembro do mesmo ano, ele voltou a se lamentar sobre a questão da leitura (agora do suprimento de revistas): "Você também não me escreveu nada a propósito das publicações periódicas que eu deveria receber da Livraria Sperling". Tratava-se de sua mudança de endereço de Roma a Turi que precisava ser informada à livraria.

Diversas são as cartas onde ele mostra sua preocupação insistente com os livros. Ora está a falar a Tatiana (20/08/28) de um "pacote de livros". Em seguida (3/11/28) reclama o envio de seus livros que estavam nas mãos de seu advogado, ou se refere aos livros da Slavia, editora que ele acompanhava atentamente. A Slavia, dirigida por A. Polledoro, difundiu, entre 1926 e 1938, a literatura russa e eslava na Itália. 


\section{Fontes Socialistas}

Pelos autores mais citados nos Quaderni também se poderia fazer um levantamento da circulação editorial de alguns autores muito lidos na Itália. Por exemplo, Antonio Bresciani (1798-1862), um jesuíta que cultivou a novela histórica, tendo sido também o principal redator de Civiltà cattolica, publicação que continuou a existir e que Gramsci lia assiduamente. Não foi à toa que Gramsci o tenha citado muito. A obra de Bresciani teve uma repercussão européia fora do comum. Seu livro Hebreu de Verona alcançou 80 edições em poucos anos e foi traduzido ao francês, russo, alemão, inglês e castelhano. Outro autor muito citado foi A. Loria. Sua obra principal, Annalisi della proprietà capitalistica (1888) recebeu da Academia dei Lincei (Roma) o prêmio do rei. Ambos os autores eram usados por Gramsci para significar fenômenos essencialmente negativos. Já Benedetto Croce, outro entre os mais citados, era uma linguagem obrigatória. Os primeiros decênios de vida intelectual italiana no novecento foram assinalados pela "hegemonia [e Bobbio aqui faz alusão ao conceito gramsciano] de Benedetto Croce. O seu pensamento foi, con-

220 juntamente, centro de irradiação e de convergência dos movimentos intelectuais do tempo" ${ }^{17}$. Todavia, não é verdade que Gramsci tenha se afastado da leitura dos clássicos do marxismo e do socialismo, mesmo sob as duras condições carcerárias.

O número de livros que Gramsci podia ter na cela era limitado. No quarto volume da edição crítica dos Cadernos do Cárcere, preparada por Valentino Gerratana, podemos encontrar um vasto material referente aos livros que Gramsci possuía. Já no primeiro caderno carcerário encontramos uma lista de "Libri consegnati da Turi a Carlo l'11 novembre 1929". Eram 63 títulos, entre eles os de pensadores italianos como Benedetto Croce e Luigi Einaudi. Mas o grosso dessa primeira lista era composto por literatura: de Pirandello a Tolstoi, de Kipling a Dostoyevski, Tchekov e Maupassant. Mas também a chamada literatura social (ou operária ou engajada) como o próprio Tolstoi, mas também Panait Istrati, Boris Pilniaki e os best sellers da época como E. Remarque e Emil Ludwig.

\footnotetext{
${ }^{17}$ Norberto Bobbio. Profilo ideologico del novecento. Milano: Garzanti, 1990, p. 90.
} 
É preciso lembrar que a primeira lista expressa a cautela do prisioneiro, acostumando-se a novas regras de conduta que circunscreviam suas possibilidades de leitura. Mais adiante, no mesmo primeiro caderno, encontravam-se 4 livros, dentre eles o do general Krasnof, dall'aquila imperiale alla bandiera rossa (Firenze, Salani), cuja fonte e terminologia seriam usadas amiúde por Gramsci. Na lista seguinte, "Libri fatti consegnare a Tatiana a Turi il 20 febbraio 1930", havia 8 títulos com destaque para Croce e Prezzolini. Na lista seguinte, datada de 13 de março de 1930, 16 títulos, mas agora incluindo periódicos como o Almanacco letterario e autores como Marcel Proust e Plutarco. A lista de 20 de maio seguia o mesmo padrão. Só numa anotação a parte viam-se dois títulos socialistas de Leon Trotski: La révolution défigurée e Vers le capitalisme ou vers le socialisme?. Gramsci certamente não podia ter à mão os livros dos chefes do Estado Soviético, como Lênin e Stalin. Mas Trotski já havia sido expulso da União Soviética e do Partido Comunista. Ele foi mesmo publicado em italiano pela Editora Mondadori em 1930 (reedição nos anos 50, com 13 ilustrações) $)^{18}$.

No Caderno 2 há um esboço de um requerimento, datado de setembro de 1930 ("Istanza a S.E. il Capo del Governo spedita nel settembre 1930"). Esta carta é paradigmática porque revela a necessidade do prisioneiro (que tinha uma relação quase física com os livros), saber quais as suas condições de leitura. O que ele podia ou não ler. Ele conta que em junho de 1928, no cárcere judiciário de Roma, confiscaram-lhe um opúsculo de versos de Mino Maccari, notório escritor fascista. Gramsci protestou ao Tribunal Especial e conseguiu saber que somente os livros de agitação política lhe eram proibidos:

"Na Casa Penal de Turi de Bari, onde estou preso atualmente, sequestraram-me novamente o libreto de Maccari, junto com estes outros: Giuseppe Prezzolini, Mi Pare... (uma coletânea de artigos de variedade editada em 1925 por Arturo Marpicati), Oscar Wilde, Il Fantasma dei Canterville e outras duas novelas humorísticas, H. Man, Le Sujet, Ed. Kra (romance da Alemanha Guilhermina), Petronio Arbitro, Satyricon, J. London, Le memorie di un bevitore, Krasnoff, Dall'aquila imperiale alla bandiera rossa (é um romance do general dos cossacos

${ }^{18}$ Arnoldo Mondadori Editore. Catalogo Generale giugno 1956, Milano: Mondadori, p.108 
Krasnoff, emigrado tzarista em Berlim, editado por Salani de Florença); Maurice Muret, Le crépuscule des nations blanches, 1925. Tratase de livros anódinos e insignificantes, é verdade, mas trata-se para mim, que devo ainda descontar 15 anos de reclusão, de uma importante questão de princípio: saber com exatidão quais livros posso ler"19.

Gramsci aproveitava, no fim dessa carta, para pedir a concessão da leitura de Fülop Miller, Il volto del bolscevismo e a Autobiografia de Leon Trotski. Nessa missiva há toda uma estratégia sutil de diálogo entre um prisioneiro e combatente e seu algoz. Que não é necessariamente uma pessoa, mas um sistema. E Gramsci cobrava das pessoas, representantes do sistema, uma coerência com as regras do próprio sistema. Há também uma ambigüidade proposital entre crítica e aceitação das regras, bem como uma estratégia de exploração das brechas, das válvulas de escape. Como se sabe, Antonio Gramsci nunca esboçou um gesto de luta ilegal enquanto esteve no cárcere. Condenou toda a agitação ou pressão pública que se pudesse fazer a seu favor. Uma vez preso, preferia lutar num horizonte reconhecível e dentro de perspectivas bastante

222 realistas que lhe preservassem ao menos os direitos que o próprio regime fascista declarava existirem. Comportamento que, se não destoava das diretivas que o partido impunha aos seus militantes presos, também retirava qualquer veleidade de heroísmo vulgar e artificial apregoado à época ${ }^{20}$.

Por outro lado, ele jamais se rendeu ou declarou ter abandonado suas convicções políticas. Na carta, ele aproveita para simular a pouca importância dos livros pedidos, acrescenta que são politicamente neutros ou mesmo a favor do fascismo. Ora, se entre os livros pedidos há um ou mais fascistas notórios (como ele diz) e se os mesmos são insignificantes, é uma crítica bastante sutil e irônica ao próprio fascismo que se esboça através do diálogo sobre os livros. Por fim, ele volta a usar as "permissões" do sistema: se o governo italiano permitiu a publicação de dois livros sobre o bolchevismo, incluindo a autobiografia de Trostski, por que ele não os poderia ler?

\footnotetext{
${ }^{19}$ Q.C., p. 2375.

${ }^{20}$ Vide: I communisti di fronte alla polizia e di fronte ai giudici (lettera di un vecchio rivoluzionario). Paris: Edizioni del PCI, junho de 1928, 15 p.

${ }^{21}$ Norberto Bobbio. O conceito de sociedade civil. Tradução: Carlos Nelson Coutinho. Rio de Janeiro: Graal, 1982, p.32.
} 
Numa carta seguinte, a mesma "estratégia" é utilizada com mais ousadia. Gramsci gentilmente lembra ao seu interlocutor que um pedido similar ao que ora está a fazer foi recebido favoravelmente um ano antes. Uma vez mais ele explora as contradições dos dispositivos regulamentares com o próprio sistema, porque uma nova regra fixara uma tabela de publicações periódicas que os presos poderiam ler, mas excluía (ou ignorava) um conjunto de outras revistas que Gramsci já assinava há 4 anos e meio por autorização do Tribunal Especial de Defesa do Estado. No mesmo requerimento, Gramsci solicita livros mais diretamente vinculados à questão socialista: Knickebocker, O Plano quinquenal soviético. Também Le procès du parti industriel de Moscou; Trotski, La révolution défigurée e Vers le socialisme ou vers le capitalisme?. Para evitar surpresa aos superiores, ele pede as obras completas de Marx e Engels com o reparo de que já tinha autorização do Tribunal Especial para lê-las, pois já possuía em sua cela vários volumes. Por fim, para justificar o livro de Marx, Lettres à Kugelmann, com prefácio de N. Lenin, ele faz saberem que se trata de um prefácio de 1907.

O interesse de Gramsci pelo desenvolvimento da União Soviética nunca deixou de ser grande e persistente. Aparentemente, ela continuou sendo um paradigma bastante concreto para qualquer socialista marxista baseado na realidade. Seus longos comentários a respeito da doutrina de Nicolai Bukharin demonstram o quanto ele usou a linguagem da filosofia e das intrincadas discussões sobre materialismo histórico e ciência para refletir sobre a natureza política do regime soviético.

O mesmo se pode dizer do interesse pelo marxismo. Seus cadernos do cárcere mostram que ele fez exercícios de tradução de vários livros de Marx e Engels, como: Manifesto Comunista, Trabalho Assalariado e Capital, Questão Judaica, Sagrada Família e Contribuição Para a Crítica da Economia Política. Ora, se é verdade que Antonio Gramsci foi um marxista sui generis, muito ocupado com aquilo que ele entendia ser o princípio leninista ("análise concreta de uma situação concreta"), ele não descurou do conhecimento teórico dos clássicos do marxismo. Os títulos citados de Marx e Engels, somados, são 32 nos Cadernos.

A idéia de que Gramsci teria abandonado o axioma básico do chamado materialismo histórico, a saber, a primazia em última instância da infra-estrutura ou base em relação às superestruturas, asseverando uma determinação da sociedade civil (em termos gramscianos) sobre a totalidade da vida social, foi propugnada por Norberto Bobbio ${ }^{21}$. Outros preferiram um Gramsci teórico apenas da política. Mas tanto suas inúmeras e dispersas notas sobre economia, 
quanto os livros que ele compulsou sobre o assunto, confirmam o contrário. Ele não deixou passar ao largo suas inclinações muito ortodoxas neste assunto. Ele citou pelo menos seis diferentes versões e/ou resumos de $O$ Capital de Karl Marx, além do original alemão.

Ora, Il Capitale foi editado na Itália em versões resumidas ou mesmo o primeiro volume em tradução de segunda mão desde 1879, quando Carlo Cafiero publicou seu resumo da obra de Marx. As duas editoras que publicaram Marx nos primeiros decênios do século XX foram Nerbini, de Florença e Società Editrice Avanti, de Milão. Nerbini publicou a versão de Ettore Fabietti $^{22}$. As Opere de Marx, Engels e Lassale dirigidas por Ettore Ciccotti, foram publicadas primeiro por Remo Sandron e, depois, por Luigi Modigliani em Milão. Gramsci fez o seguinte comentário a respeito da atividade editorial de Remo Sandron:

"Nas edições Remo Sandron muitos livros para esta rubrica. Duas direções. Sandron teve um momento de caráter 'nacional': publicou muitos livros que se referem à cultura nacional e internacional (edições originais de obras de Sorel); e é editor 'siciliano', isto é, publicou livros sobre questões sicilianas, especialmente ligadas aos eventos de 1893-94. Caráter positivista de uma parte e de outra sindicalista das publicações de Sandron. Muitas edições esgotadas, para pesquisar só em antiquários" ${ }^{23}$.

Vê-se que o conhecimento até mesmo da circulação e das vicissitudes editoriais da obra de Marx era posto em relevo por Gramsci. Ele se referiu mais de 200 vezes a Marx nos seus cadernos e mais ou menos a metade disso a Engels. Referiu-se mais ainda a Croce, é certo, e bastante a Maquiavel e Hegel. Ainda assim, Gramsci tinha que eludir e iludir a censura carcerária não a respeito de nomes como Bresciani ou Missiroli, mas em relação a Marx e Engels, muitas vezes chamados de os corifeus ou fundadores da filosofia da Práxis, a Stalin

\footnotetext{
${ }^{22}$ Ettore Fabietti é citado nos Quaderni $(\mathrm{Q} 2$, , 88) por um artigo sobre bibliotecas populares de Milão, onde mostra que os operários eram os melhores usuários: cuidavam dos livros e não os perdiam, diferentemente de outras categorias de leitores (empregados, estudantes, donas de casa).

${ }^{23}$ Q.C., p. 980.
} 
(Bessarione), a Trotski (Bronstein) e, especialmente, a Lenin, citado como Ilitch ou o discípulo dos fundadores da filosofia da práxis (o marxismo).

\section{Fortuna Crítica}

A discussão de Gramsci sobre os livros e editoras encontra-se apenas nos Cadernos do Cárcere. Isso traz um problema para o historiador: as adições desses textos implicam uma leitura e um direcionamento ideológico. Gramsci ele mesmo nunca quis editar um livro e é bastante plausível supor que jamais publicaria suas notas carcerárias no estado em que as deixou. Quando recebeu uma proposta, nos anos 20, para reunir seus artigos em livro, ele recusou sob o argumento de que seus textos eram apenas circunstanciais, posto que ele era sempre um intelectual em diálogo constante com os acontecimentos e os personagens de ocasião. Estampava seus artigos apenas em jornais.

No Cárcere sua escritura sofreu uma alteração fundamental. Ele escrevia Für Ewig (para a eternidade) como dizia. Escreveu reflexões mais demoradas em 33 cadernos. Trabalhava neles muitas vezes ao mesmo tempo, o que em alguns casos impede que saibamos a ordem cronológica dos textos. Reescrevia passagens inteiras às vezes mudando uma ou outra palavra. Como editar uma obra assim? Este problema foi enfrentado por Palmiro Togliatti.

A História da edição dos Cadernos começou já em vida de Gramsci. No dia 7 de dezembro de 1933, após pedidos insistentes e uma campanha internacional a respeito de suas precárias condições de saúde, Antonio Gramsci foi finalmente transferido da prisão de Turi para uma clínica em Formia. A preocupação do detento era com seus livros. Especialmente com seus cadernos manuscritos. Temia que a direção do cárcere lhe confiscasse tudo o que havia escrito ou lido. Preparou uma operação: enquanto ele mesmo distraía seus carcereiros, um jovem amigo de cela, Gustavo Trombetti, enfiava os cadernos embaixo das roupas, no fundo da mala.

Quando Antonio morreu em 27 de abril de 1937, ele deixou na clínica onde passou os últimos dias lancinantes da vida, os seus livros. Livros lidos e escritos. Livros do presente e do passado. E aqueles do futuro, de sua lavra, os cadernos que viriam a ser publicados. Piero Sraffa, seu amigo e correspondente, interpelou o centro exterior do Partido Comunista da Itália sobre o que fazer com os manuscritos gramscianos. Palmiro Togliatti (cujo pseudônimo era Ercoli) escreveu-lhe falando com veemência da herança política e literária de Antonio. Decidiu-se enviá-los a Giulia, esposa de Antonio, em Moscou 
(o que significava, em verdade, fazê-los chegar a Ercoli). Escrevendo a Tatiana, cunhada de Antonio, Piero a aconselhou a cuidar muito da segurança do transporte dos manuscritos. Seria preciso um transporte "seguro". Quando Piero chegou à Itália, em junho, ele cuidou para que os cadernos do cárcere ficassem sob custódia no cofre de um banco (Banca commerciale). O presidente do banco era um antifascista amigo de Piero.

Os cadernos permaneceram no cofre por um $\mathrm{ano}^{24}$. Neste período Tatiana fez várias instâncias a fim de tomar posse também dos livros que Antonio possuía na prisão. Depois disso, providenciou um baú no qual os cadernos chegaram a Moscou. Lá, Vincenzo Bianco, representante italiano na Internacional Comunista, retirou pessoalmente os escritos e os entregou a Ercoli. Foi assim que os cadernos de Antonio Gramsci foram salvos.

Palmiro Togliatti publicou os Cadernos do Cárcere entre 1948 e 1951. Ele reagrupou as notas de Gramsci por grandes temas. Assim, favoreceu uma leitura "fácil", militante, mas também dirigida. Foram cinco livros: Maquiavel, o Estado e a Política Moderna; Literatura e Vida Nacional; Passado e Presente; O Materialismo Histórico e a Filosofia de Benedetto Croce; O Risorgimento.

226 Além disso, foram publicadas também as Cartas do Cárcere. Argumentou-se que, embora essa seja ainda a mais importante edição dos textos gramscianos, ela está ligada à chamada via nacional para o socialismo (estratégia do Partido Comunista Italiano no pós-guerra). Agrupar as críticas de Gramsci a Croce e não as críticas a Bukharin, revela uma escolha. No segundo caso, seria mostrar um Gramsci que questionava o materialismo soviético, por exemplo. Além disso, os Cadernos não foram escritos com unidades temáticas. Foi feito de maneira fragmentada mas sob o prisma fundamental da história política.

Em 1975, Valentino Gerratana publicou os textos na sua "ordem espacial", ou seja, como eles aparecem nos cadernos originais. Obra mais "difícil" de ler e que interessou bem mais aos especialistas e abriu uma longa discussão teórica, conceitual e, nos anos 80-90, também filológica. Gianni Francioni pretendeu restabelecer a "ordem cronológica" dos textos ${ }^{25}$. Ainda hoje se discute a perti-

\footnotetext{
${ }^{24}$ Paolo Spriano. Gramsci in carcere e il partito. Roma: L'Unità, 1988, p.104-5.

${ }^{25}$ Vide: Guido Liguori. "El debate sobre Gramsci en el cambio de siglo”. In: Dora Kanoussi (Org). en America. II Conferência Internacional de Estudios Gramscianos. México, D.F.: Plaza y Valdes, 2000, p. 307.
} 
nência de uma edição completa e rigorosa (do ponto de vista filológico) dos textos de Gramsci. O exemplo de suas análises sobre a circulação dos livros pode servir para iluminar a edição crítica de seus próprios textos. É de se duvidar que se consiga um dia editar os Cadernos como Gramsci os pensou enquanto escrevia. Mesmo com os avanços da crítica literária neste tópico. Isso permanece sendo um problema. Mas também revela a riqueza desse pensador e homem de ação tão notável que resistiu a todas as tempestades que varreram muitos autores supostamente identificados com o marxismo.

\section{Referências Bibliográficas}

BOBBIO, Norberto. O conceito de sociedade civil. Tradução: Carlos Nelson Coutinho. Rio de Janeiro: Graal, 1982. Profilo ideologico del novecento. Milano: Garzanti, 1990.

BRUNACCI, A. Dizionario generale di cultura. Torino: Libreria Editrice, 1915. BUTTIGIEG, Joseph. "O método de Gramsci” In Educação em foco, Universidade Federal de Juiz de Fora, V. 5, N. 2, fevereiro de 2001.

CANFORA, Luciano. Libro e libertà. Bari: Laterza, 1994.

CARONE, Edgard. O marxismo no Brasil. Rio de Janeiro: Dois Pontos, 1982.

DEAECTO, Marisa e SECCO, Lincoln. "A Difusão dos Livros Marxistas no Brasil”. In: Coggiola, O. (Org). América Latina. São Paulo: Xamã, 2003.

GRAMSCI, Antonio. Lettere dal Carcere. Torino: Einaudi, 1978 Novas cartas de Gramsci e algumas de Piero Sraffa. Rio de Janeiro: Paz e Terra, 1987.

Quaderni del carcere. A cura di Valentino Gerratana. Torino: Einaudi, 1977.

LIGUORI, Guido. "El debate sobre Gramsci en el cambio de siglo". In: Dora Kanoussi (Org). En America. II Conferência Internacional de Estudios Gramscianos. México, D.F.: Plaza y Valdes, 2000.

MARX, Karl. Oeuvres. Économie. Édition établie par Maximilien Rubel. Paris: Gallimard, 1965 (Bibliothèque de la Pléiade).

PETTINATO, Concetto. "Libri, editori ed autori”, La Lettura, Revista Mensile del Corriere della Sera, N. 10, outubro de 1910. 
RUBEL, Maximilien. Karl Marx: essai de biographie intellectuelle. Paris: Marcel Rivière, 1957.

SANTORO, Marco. Storia del libro italiano. Milano: Editrice Bibliografica, 2000.

SECCO, Lincoln. Gramsci e o Brasil: Recepção e Difusão de suas Idéias. São Paulo: Editora Cortez, 2002.

SPRIANO, Paolo. Gramsci in carcere e il partito. Roma: L'Unità, 1988.

VÁRIOS AUTORES. Arnoldo Mondadori Editore. Catalogo Generale giugno 1956, Milano: Mondadori,, 1956.

VÁRIOS AUTORES. Caro Bonpiani. Lettere com l'editore. Milano: Bonpiani, 1988.

VÁRIOS AUTORES. I communisti di fronte alla polizia e di fronte ai giudici (lettera di un vecchio rivoluzionario). Paris: Edizioni del PCI, junho de 1928. 